\title{
SOUTH CAROLINA HEALTH DISPARITIES - FACTS
}

For too many Americans, life expectancy is impacted by gender, income, ethnicity, education and location. AARP South Carolina is fighting to advocate for

programs that enable people to live and age with dignity and purpose.

Disparities among Black people 50+ in South Carolina are found in:

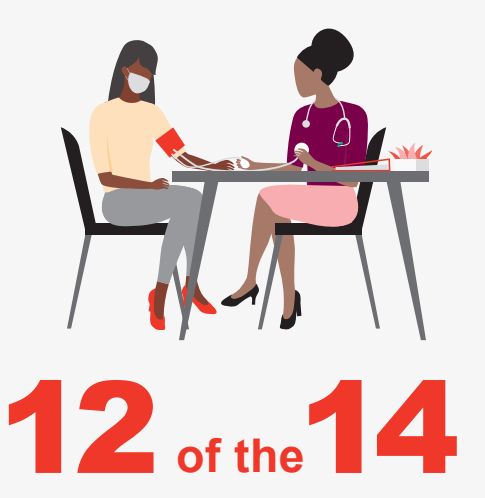

leading causes of morbidity and mortality
EXAMPLES OF DISPARITIES AND

SOCIAL DETERMINANTS OF HEALTH

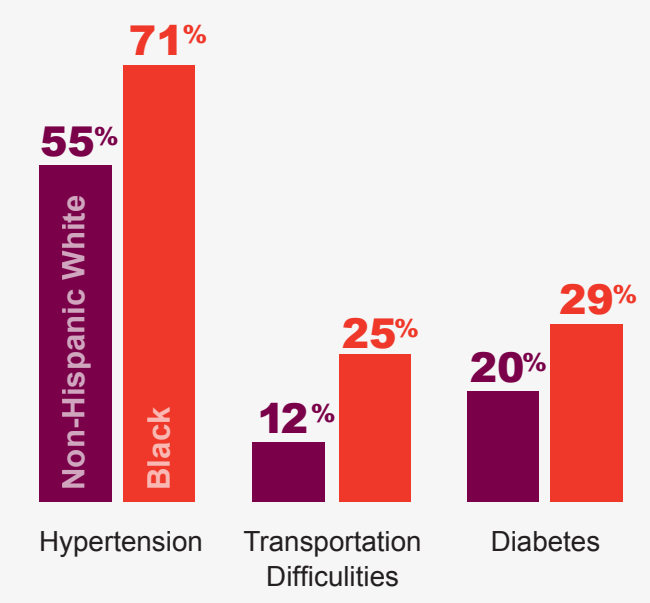

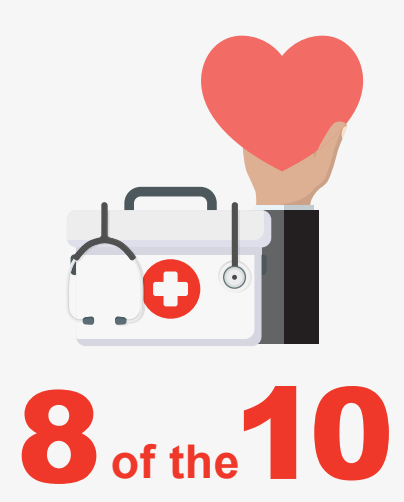

social determinants of health

\section{Black people are also more likely to suffer from these conditions ...}

HEART DISEASE

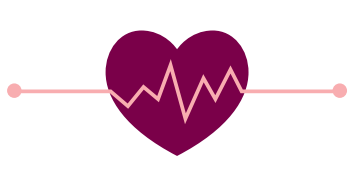

$2 \%$ higher

death rate for Black people vs. non-Hispanic

White people

\section{ALZHEIMER'S/DEMENTIA}

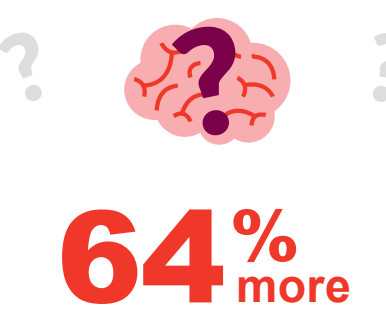

likely to have Alzheimer's disease and related dementias in comparison to White people
HUNGER
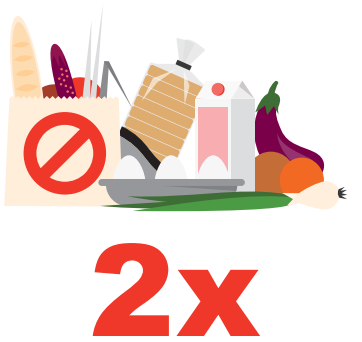

the risk of hunger for Blacks and Hispanics

PROSTATE CANCER
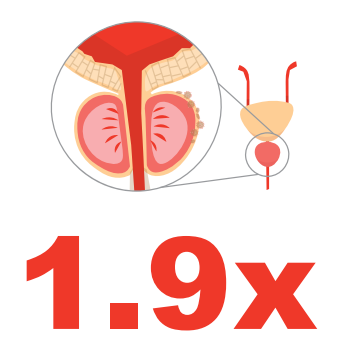

more likely to

get prostate cancer in comparison to White people
STROKE

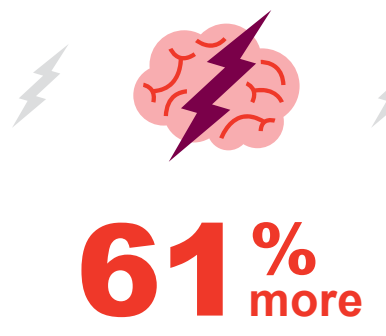

likely to die from stroke in comparison

to White people

COLORECTAL CANCER

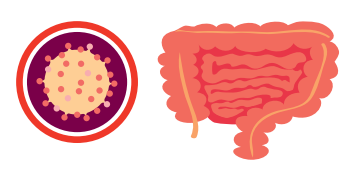

$2 \%$ higher

chance to get colorectal cancer for Black people vs. non-Hispanic White people

\section{Social determinants of health that significantly contribute to health disparities in older Black people}

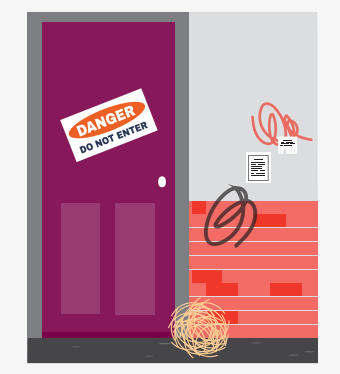

UNSAFE NEIGHBORHOODS

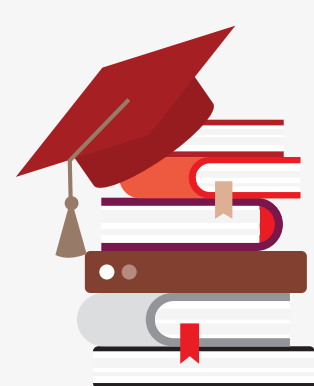

LACK OF HIGH SCHOOL EDUCATION

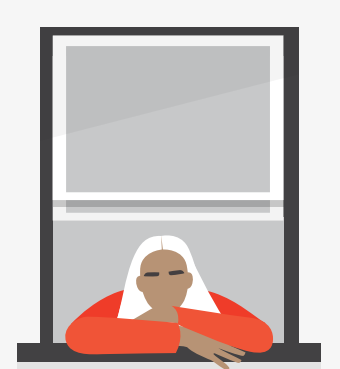

POOR HOUSING

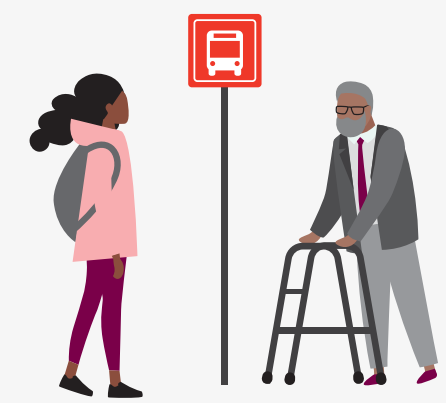

LACK OF

TRANSPORTATION 